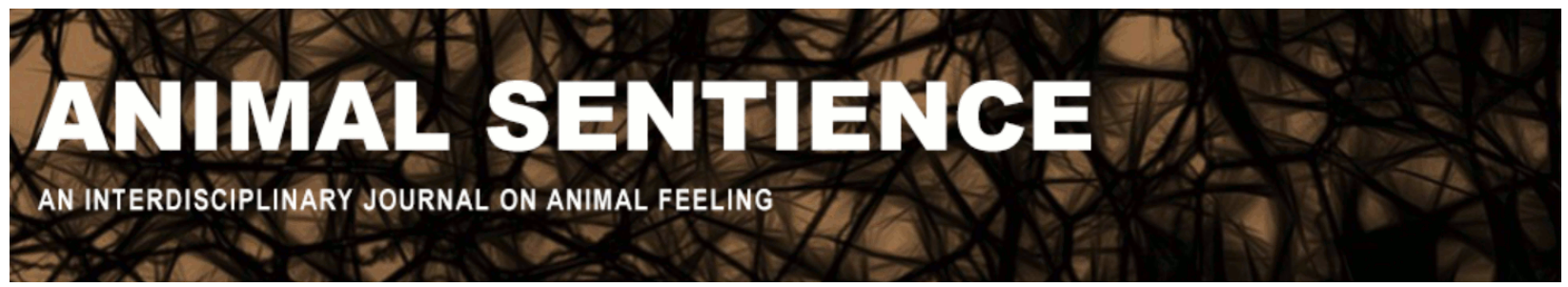

Bekoff, Marc and Pierce, Jessica (2016) Animal welfare cannot adequately protect nonhuman animals: The need for a science of animal well-being. Animal Sentience 7(2)

DOI: $10.51291 / 2377-7478.1080$

Date of submission: 2016-01-15

Date of acceptance: 2016-01-18

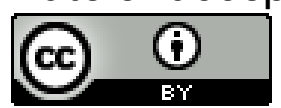




\title{
Animal welfare cannot adequately protect nonhuman animals: The need for a science of animal well-being
}

Commentary on $\mathrm{Ng}$ on Animal Suffering

\author{
Marc Bekoff \\ Ecology and Evolutionary Biology \\ University of Colorado, Boulder \\ Jessica Pierce \\ Center for Bioethics and Humanities \\ University of Colorado Anschutz Medical Campus, Denver
}

\begin{abstract}
A focus on animal welfare in the use of nonhuman animals in the service of human economic and scientific interests does not and cannot adequately protect (nonhuman) animals. It presupposes that using other animals for human ends is acceptable as long as we try our best to improve the welfare of the animals we use. We argue instead for a "science of animal wellbeing" in which the protection of animal needs is not subordinated to human economic or scientific interests.
\end{abstract}

\begin{abstract}
Marc Bekoff Marc.bekoff@gmail.com is former Professor of Ecology and Evolutionary Biology at the University of Colorado, Boulder, and co-founder with Jane Goodall of Ethologists for the Ethical Treatment of Animals. He has won many awards for his scientific research including the Exemplar Award from the Animal Behavior Society and a Guggenheim Fellowship. Marc has published more than 1,000

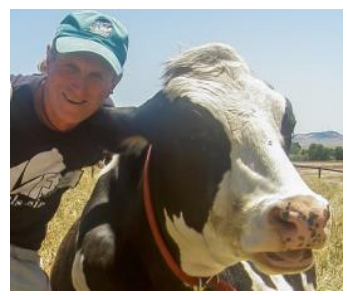
essays (popular, scientific, and book chapters), 30 books, and has edited three encyclopedias. His latest book is Rewilding Our Hearts: Building Pathways of Compassion and Coexistence. marcbekoff.com
\end{abstract}

Jessica Pierce jessicapierce.net@gmail.com, bioethicist, is the author of The Last Walk: Reflections on Our Pets at the Ends of Their Lives. Other books include Wild Justice: The Moral Lives of Animals; Contemporary Bioethics: A Reader with Cases; The Ethics of Environmentally Responsible Health Care; and Morality Play: Case Studies in Ethics. Her forthcoming book is Run, Spot, Run: The Ethics of Keeping Pets. http://jessicapierce.net

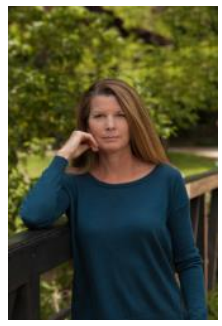

Economist Yew-Kwang Ng (2016) makes it clear in his target article that animal welfare as it is usually practiced does not and cannot adequately protect (nonhuman) animals. Early in his paper Ng writes, "There are some simple, commonsense methods that can help reduce animal 
suffering enormously at little cost - or even a net gain - to humans." Ng is quite right. Surely we should seek to address the suffering of animals when it costs us nothing. But don't we have considerably stronger responsibilities to animals? Shouldn't we address human-induced suffering wherever it occurs, even if remedying it involves some constraints on human economic or scientific interests? Ng assumes, quite in line with the broader ideology of animal welfare, that human industry is more important than the well-being of animals. This has been called "welfarism" (Donaldson \& Klymicka 2011), and the reason it is inadequate is that it consistently sustains the status quo, subordinating the protection of the life/death/suffering interests of nonhuman animals to the economic/scientific interests of humans. This generates specious and self-serving rationales - often couched in technical jargon and cast as objectivity, along with expressions of compassion - that amount to justifying why it's perfectly permissible to do this or that even if it causes animals to suffer and die.

Welfarism acknowledges the moral significance of animal pain and suffering but holds that inflicting suffering on animals is acceptable in the service of human needs and desires. Welfarists seek ways to reduce egregious suffering in animals without challenging the basic premise, namely, that animals are here for us to use as we see fit.

$\mathrm{Ng}$ notes that we cannot be $100 \%$ sure that other animals feel. But philosophers have pointed out that we cannot have $100 \%$ certainty about other humans either, because of the "otherminds problem" (Sober 2000; Farah 2008). The weight of the evidence from evolutionary biology and large bodies of detailed comparative evidence (including the work of Donald Broom, 2016, reported in this journal), together with grounded common sense, all indicate with high probability that animals with nervous systems are indeed sentient, meaning that they feel. For some users of animals, any lack of certainty provides a further excuse for continuing to do what industry has been doing for years on end, namely, harming animals and claiming it's okay not only because the welfarist calculus (human needs and desires > animal needs and desires) says so - but also because we cannot even be $100 \%$ sure that animals have needs and desires at all. Others who use animals claim instead that we cannot know for sure what other animals' needs and desires are. This too is a standard welfarist argument. Yet it seems evident that animals, including ourselves, want to live in peace and safety, free of pain, suffering, and death. Undoubtedly there are individual differences even among members of the same species, but it's safe to say that other animals don't want to be used and abused, either in the interests of the human food (or other) industry or in the interests of science. Indeed, as with us, other animals' vital interests are their own.

Professor Ng concludes his essay by writing, "In closing, my view on making an initial distinction between wild and farmed animal welfare, and on giving initial priority to reducing harm to animals when it is virtually costless and does not impede scientific advances, is just a starting position. Palpable progress with these relatively easier welfare problems will then serve as a foundation for extending our future efforts in eliminating all needless non-human and human animal suffering on the planet." 
These sentences and the implicit values underlying them illustrate why welfarism is insufficient. The premise that it is right for human economic and scientific interests to trump animals' vital interests and well-being is never called into question: Why should we not simply refrain from intentionally subjecting others - human or non-human - to harm, where our own lives are not even at stake?

One possible response is to tighten the loopholes, so that we make careful distinctions between the vital interests of humans (e.g., life-saving biomedical research) and the non-vital interests of humans (e.g., a new fur coat for opera season or streets lined with Chik-fil-A). Only vital human interests could then be used to justify inflicting suffering, overriding the freedom of animals to live their own lives on their own terms. This would be a huge improvement, to be sure. Nonetheless, it remains deeply troubling to devalue the vital interests of any sentient being.

Ng's phrase "virtually costless" is troublesome because there are always costs to the animals, and this loophole again allows economic interests to override the lives and well-being of animals who are being used and abused.

\section{Replacing the science of animal welfare with the science of animal well-being}

In a forthcoming book (Pierce and Bekoff 2017) we argue that animal protection needs an animal-centered "science of animal well-being." We suggest that following the principles of the rapidly growing international field called "compassionate conservation," namely, "First do no harm" and "the life of every individual matters" provides a promising and workable blueprint for the needed shift from welfarism to a more a more compassionate moral framework.

Improving the welfare of animals that are being harmed for economic or scientific purposes does not and cannot adequately protect animals because it presupposes that using other animals for human ends is acceptable as long as we do the best we can. "Doing the best we can" does not do away with animal pain and suffering as long as humans use animals for human ends. While Professor Ng clearly sees the need to address animal suffering, he aims far too low and stops far short of the goal, and in the end favors continuing to use the paradigm of animal welfare along with its various loopholes that favor human interests over those of other animals. Surely we can and must do more. 


\section{References}

Broom, D. M. (2016). Considering animals' feelings: Précis of Sentience and animal welfare Animal Sentience 2016.005.

Donaldson, S., \& Kymlicka, W. (2011). Zoopolis: A political theory of animal rights. Oxford University Press.

Farah, M. J. (2008). Neuroethics and the problem of other minds: Implications of neuroscience for the moral status of brain-damaged patients and nonhuman animals. Neuroethics, 1(1), 918.

$\mathrm{Ng}$, Y-K. (2016) How welfare biology and commonsense may help to reduce animal suffering. Animal Sentience 2016.007.

Pierce, J., \& Bekoff, M. (2017) Born free? Compassion for animals in the anthropocene. Beacon Press, Boston.

Sober, E. (2000). Evolution and the problem of other minds. Journal of Philosophy, 97(7), 365386. 